Caruana Emma (Orcid ID: 0000-0003-4706-8291)

Parrish Emma (Orcid ID: 0000-0003-1937-8145)

Chanen Andrew (Orcid ID: 0000-0003-4468-622X)

Bryce Shayden (Orcid ID: 0000-0001-6425-9861)

WORK AND STUDY AMONG YOUTH WITH MENTAL ILLNESS

\title{
Vocational Engagement among Young People Entering Mental Health Treatment Compared with their General Population Peers
}

\author{
Caruana, E. ${ }^{1}$, Farhall, J. ${ }^{1,2}$, Cotton, S.M. ${ }^{3,4}$, Parrish, E. ${ }^{3,4,6}$, van-der-EL, K..$^{3,4}$ \\ Davey, C.G. ${ }^{3,4,5}$, Chanen, A.M. ${ }^{3,4,5}$, Bryce, S.D. ${ }^{3,4,7}$, Killackey, E. ${ }^{3,4}$ \& Allott, K. ${ }^{3,4}$.
}

\author{
Affiliations: \\ ${ }^{1}$ La Trobe University, Victoria Australia \\ ${ }^{2}$ North Western Mental Health, Victoria Australia \\ ${ }^{3}$ Orygen, The National Centre of Excellence in Youth Mental Health, Victoria Australia \\ ${ }^{4}$ Centre for Youth Mental Health, The University of Melbourne, Australia \\ ${ }^{5}$ Orygen Youth Health, Victoria Australia \\ ${ }^{6}$ Northeastern University, Boston, MA, USA \\ ${ }^{7}$ Monash University, Victoria Australia
}

\section{Corresponding Author:}

Dr Kelly Allott

Senior Research Fellow

Orygen, The National Centre of Excellence in Youth Mental Health

This is the author manuscript accepted for publication and has undergone full peer review but has not been through the copyediting, typesetting, pagination and proofreading process, which may lead to differences between this version and the Version of Record. Please cite this article as doi: 10.1111/eip.12712

This article is protected by copyright. All rights reserved. 
35 Poplar Road, Parkville, Victoria Australia 3052

Tel: +61407365600

Email: kelly.allott@,orygen.org.au

\begin{abstract}
Aim: To compare rates of vocational engagement for youth entering specialist mental health treatment with the general population. Methods: A file audit retrieved vocational data for 145 youth aged 15-25 entering treatment. Clinical and population data were stratified by age and sex and compared between cohorts. Results: Compared to the population, young people entering mental health treatment were less likely to have completed at least Year 11 in school (77\% vs. $42 \%, p<.001)$; and demonstrated higher rates of 'Not in Education, Employment or Training' (NEET; 9\% vs. 33\%, p<.001). Individuals aged 15-18 years entering treatment experienced greater rates of educational disengagement than the population $(30 \%$ vs. $11 \%, p<.001)$, whereas people aged 19-25 years showed higher unemployment rates (52\% vs. 35\%, $p=.003)$.

Conclusions: Youth entering specialist mental health treatment have marked levels of vocational disengagement compared to demographically-matched peers. Early vocational intervention for these young people is essential.
\end{abstract}

This article is protected by copyright. All rights reserved. 
Keywords: Mental illness; youth; employment; education; vocational disengagement.

This article is protected by copyright. All rights reserved. 


\section{Introduction}

Vocational participation is a core component of functional recovery in severe mental illness (Waghorn \& Lloyd, 2005). Adolescence and early adulthood is a critical period for education attainment and initial career-based employment. The peak onset of mental illnesses occurring during this period pose significant risks to these normative developmental roles (Gore et al, 2011; Killackey et al., 2006; Kessler et al., 1995). Accordingly, the need for early targeted vocational intervention has been recognized in international policy (ACAMH Special Interest Group in Youth Mental Health, 2013) and by consumers (Cotton et al., 2011; Ramsay et al., 2011).

Understanding rates and types of vocational engagement in young people at entry to mental health treatment services is critical for early intervention and optimizing functional outcomes. This is often the first opportunity for interventions to be delivered (Jackson and McGorry, 2009). In-depth knowledge of vocational rates, however, appears limited. Most existing studies are based on populations with chronic mental disorders, which may not adequately reflect rates in young people. There is also little consistency regarding when (e.g., first-contact or following engagement with treatment services) and how vocational outcomes are measured (e.g., education/employment domains combined or separated). Finally, many studies do not incorporate general population comparison samples, which is essential for understanding the relative severity of the issue. 
We recently conducted a file audit of people aged 15-25 years entering specialist mental health treatment for severe depression ( $n=50$ ), borderline personality disorder (BPD, $n=50)$ and psychosis ( $n=50$; Caruana et al., 2017). Rates of disengagement from employment, education or training were not significantly different between the diagnostic groups, emphasizing the need for vocational interventions across disorders. While the need for vocational support (for both education and employment) appeared high across all diagnostic categories, the relative degree of vocational disruption relative to the general population of youth is unknown. Thus, the aim of this study was to extend our previous findings (Caruana et al., 2017) by comparing rates of education and employment of youth entering specialist mental health treatment with demographically-matched young people in the general population. This may assist in helping determine the need for vocational interventions in youth specifically (Waghorn et al., 2011). It was hypothesized that youth entering mental health treatment would have significantly lower rates of engagement in education and employment compared with demographically-matched peers from the general population.

\section{Methods}

This study was an extension of Caruana et al. (2017), which involved auditing clinical files of patients entering treatment at Orygen Youth Health (OYH) in 2011. OYH is a specialist, State Government-funded youth mental health program serving the north-western areas of metropolitan Melbourne, Australia. Each file contained information compiled during the young person's treatment period. Comparative population data were obtained from the 2011 Australian 
Census and 2011 Survey of Education and Work, which were accessed through the Australian Bureau of Statistics (www.abs.gov.au).

The sample comprised 145 young people, aged 15 to 25 years attending one of three specialised treatment programs for first-episode psychosis, severe and complex mood disorders or BPD. Population data were obtained for all 15- to 25-year-olds residing in the same (or similar) geographical catchment area. Stratification by age (15-18 years and 19-25 years) and sex was undertaken to adjust for clinical and vocational differences between the groups. The final treatment program sample was randomly selected from each strata.

Files from the three clinics were combined to create a single clinical sample given the finding of minimal diagnostic differences in vocational functioning in the previous study (Caruana et al., 2017). Group outcomes were compared initially, and again following stratification by age and age by sex. Familywise Bonferroni corrections were applied for related analyses. Inter-rater reliability estimates were in 'almost perfect agreement' (Viera \& Garrett, 2005): Cohen's kappa for current education and employment status as well as the quality and type of engagement outcomes ranged from 0.90-1.0 $(p<.001)$. The flow of participant files, details of the file audit tool and extraction procedures, and more specific methodological details are presented in Caruana et al. (2017).

\section{Results}


Of the 145 clinical files audited, $48 \%(n=70)$ were aged $15-18$ years $(41 \%, n=29$ male; $59 \%, n=41$ female) and 52\% (n=75) were aged $19-25$ years $(39 \%, n=29$ male; $61 \%, n=46$ female). The census age- and geographically-matched population group comprised 182,473 individuals. The Survey of Education and Work surveyed around 39,800 15-74 year olds, from which inferences were made for 871,100 Victorians aged $15-25$ years. The population benchmark comprised 30\% $(n=55,394)$ individuals aged $15-18$ years $(51 \%, 28,284$ male; $49 \%$, $27,110$ female $)$ and $70 \%(\mathrm{n}=127,079)$ individuals aged $19-25$ years $(50 \%, 64,161$ male; $50.0 \%$, 62,918 female). Demographic characteristics stratified by age and sex are shown in Table 1 . The proportion of people that were married or de facto, born in Australia, or Aboriginal or Torres Strait Islander did not differ between the clinical and population samples. However, females aged 15-18 in the clinical sample were less likely to live with their parents than the population.

\section{(INSERT TABLE 1)}

Information on highest level of education completed, current education status, unemployment, and whether the person was 'Not in Education, Employment or Training' (NEET), is presented in Table 2. Overall, significantly fewer people aged 19-25 in the clinical sample had completed a minimum of Year 11 than the population, which was particularly evident among males. Both males and females aged 15-18 in the clinical sample were less likely to be currently studying than population peers. Higher rates of unemployment in people aged 1925 were revealed in the clinical sample, particularly among females. A greater proportion of 
participants in the clinical sample were NEET relative to the population, which persisted independently of stratification.

\section{(INSERT TABLE 2)}

\section{Discussion}

Young people aged 19-25 seeking mental health treatment were less likely to have completed education to at least Year 11 (particularly males) or be currently employed (particularly females) when compared to the general population. Males and females aged 15-18 in the clinical sample were less likely be studying than their peers. Finally, young people seeking mental health treatment demonstrated significantly higher NEET rates in every strata relative to population estimates. This highlights the vocational burden of illness for young people entering mental health treatment.

With the exception of level of education completed, our findings are broadly comparable with previous studies that did not include a population comparison. Only $42 \%$ of people in this study had completed Year 11 or higher. This is lower than previously reported rates of school attainment among other general and youth samples with mental illness, which has ranged from 51-95\% (Waghorn et al., 2011; Leach and Butterworth, 2012; Isohanni et al., 2001). This difference may be due to differences between studies in sample characeristics (e.g., included age range) and education parameters utilized (e.g., categorization of educational achievement). 
Levels of unemployment and educational withdrawal are broadly comparable to past Australian research reporting rates of unemployment and disengagement in education among youth experiencing mental illness of 48-61\% (Waghorn et al., 2011; Sio et al., 2011; Cotton et al., 2017). Current NEET rates in the clinical sample (33\%) are also consistent with previous studies of youth receiving mental health treatment, with previous rates ranging between $29-33 \%$ (O'Dea et al., 2016; Sio et al., 2011). The current findings showing that compared to the population, 15-18 and 19-25 year olds entering mental health treatment experience significantly higher rates of disengagement from study and unemployment, respectively, is concerning. This is despite participation in work or study representing a common treatment goal in young people with mental illness (Cotton et al., 2011; Ramsay et al., 2011).

At present, vocational interventions are not routinely delivered as part of mental health treatment in Australia. This is despite successful trials of vocational interventions in young people with severe mental illness, which have predominantly focused on employment (e.g., supported employment; Drake et al., 2012). Most of these trials have been conducted in firstepisode psychosis, with limited research focusing on improving education outcomes for youth samples (Killackey et al., 2006; 2008; 2016). Our data support the need for direct funding of and research into and translation of vocational interventions such as Individual Placement and Support for youth with mental illness generally. A focus on tailoring interventions to the young person's age, vocational domain and personal preferences appears essential for treatment success. 
Generazability of these findings may be limited as files were audited from one mental health service. Missing data was common; 44/145 files did not describe the patient's employment status, which may not be routinely recoded by clinicians (Conus et al., 2007). Greater emphasis on documenting pre-admission vocational status, even if unlikely to impact acute treatment options, may be required to assist with discharge and rehabilitation planning once clinical symptoms are better managed. This study was also cross-sectional; rates of change in vocational functioning over time is important to consider in future studies. Finally, data were collected retrospectively, which precludes assessment of reliability of information recorded in files.

In conclusion, rates of educational achievement and engagement, employment and overall vocational engagement are significantly poorer in young people entering specialist mental health treatment than demographically-matched peers. Consequently, there is a need for assessment of vocational engagement and early interventions in these young people. Investigating the type of vocational interventions that are most beneficial to young people with mental illness is a critical research priority and essential for optimizing functional recovery. 
Funding: Specific funding provided for the development of this manuscript was obtained via EC's Doctor of Clinical Psychology budget from La Trobe University. EC is supported by an Australian Postgraduate Award from La Trobe University. SC and CGD are each supported by a Career Development Fellowship from the National Health and Medical Research Council (NHMRC; APP1061998 and APP1061757, respectively). EP was supported by a Presidential Global Scholarship from Northeastern University. AC receives funding from the National Health and Medical Research Council. KA is supported by the Ronald Philip Griffiths Fellowship from the Faculty of Medicine Dentistry and Health Sciences, The University of Melbourne. EK receives funding from NHMRC (APP1051891) and the Faculty of Medicine at The University of Melbourne. He has received funding related to this area of work from Australian Rotary Health, Australian Research Council (ARC), Ronald Philip Griffith Fellowship and NHMRC.

Declaration of conflicting interests statement: The authors declare that there is no conflict of interest. 


\section{References}

ACAMH Special Interest Group in Youth Mental Health. (2013) The International Declaration on Youth Mental Health Available at: http://www.iaymh.org/f.ashx/8909_IntDeclaration-YMH_print.pdf.

Caruana, E., Cotton, S. M., Farhall, J., Parrish, E. M., Chanen, A., Davey, C. G., . . Allott, K. (2017). A comparison of vocational engagement among young people with psychosis, depression and borderline personality pathology. Community Mental Health Journal, 111. https://doi.org/10.1007/s10597-017-0197-5.

Conus P, Cotton S, Schimmelmann BG, et al. (2007) The First-Episode Psychosis Outcome Study: premorbid and baseline characteristics of an epidemiological cohort of 661 firstepisode psychosis patients. Early Intervention in Psychiatry 1: 191-200.

Cotton S, Lambert M, Schimmelmann B, et al. (2017) Predictors of functional status at service entry and discharge among young people with first episode psychosis. Social Psychiatry and Psychiatric Epidemiology: 1-11. doi: 10.1007/s00127-017-1358-0

Cotton SM, Luxmoore M, Woodhead G, et al. (2011) Group programmes in early intervention services. Early Intervention in Psychiatry 5: 259-266.

Drake RE, Bond GR and Becker DR. (2012) Individual placement and support: an evidencebased approach to supported employment. Oxford University Press.

This article is protected by copyright. All rights reserved. 
Gore, F.M., Bloem, P.J., Patton, G.C., Ferguson, J., Joseph, V., Coffey, C., Sawyer, S.M., Mathers, C.D., 2011. Global burden of disease in young people aged 10-24 years: a systematic analysis. The Lancet 377, 2093-2102.

Jackson HJ and McGorry PD. (2009) The Recognition and Management of Early Psychosis: A Preventative Approach. Second ed. New York: Cambridge University Press.

Kessler RC, Foster CL, Saunders WB, et al. (1995) Social consequences of psychiatric disorders, I: Educational attainment. American Journal of Psychiatry 152: 1026-1032.

Killackey E, Allott K, Woodhead G, et al. (2017) Individual placement and support, supported education in young people with mental illness: an exploratory feasibility study. Early Intervention in Psychiatry 11(6): 526-531.

Killackey E, Jackson H, Gleeson J, et al. (2006) Exciting career opportunity beckons! Early intervention and vocational rehabilitation in first-episode psychosis: employing cautious optimism. Australian and New Zealand Journal of Psychiatry 40: 951-962.

Killackey E, Jackson HJ and McGorry PD. (2008) Vocational intervention in first-episode psychosis: individual placement and support v. treatment as usual. The British Journal of Psychiatry 193: 114-120.

O’Dea B, Lee RS, McGorry PD, et al. (2016) A prospective cohort study of depression course, functional disability, and NEET status in help-seeking young adults. Social Psychiatry and Psychiatric Epidemiology 51: 1395-1404.

This article is protected by copyright. All rights reserved. 
Ramsay C, Broussard B, Goulding S, et al. (2011) Life and treatment goals of individuals hospitalized for first-episode nonaffective psychosis. Psychiatry Research 189: 344-348.

Sio IT, Chanen AM, Killackey EJ, et al. (2011) The relationship between impulsivity and vocational outcome in outpatient youth with borderline personality features. Early Intervention in Psychiatry 5: 249-253.

Viera AJ and Garrett JM. (2005) Understanding interobserver agreement: the kappa statistic. Family Medicine 37: 360-363.

Waghorn G, Chant D, Lloyd C, et al. (2011) Earning and learning among Australian community residents with psychiatric disorders. Psychiatry Research 186: 109-116.

Waghorn, G., \& Lloyd, C. (2005). The employment of people with mental illness. Advances in Mental Health, 4(2), 129-171.

This article is protected by copyright. All rights reserved. 
Table 1

Comparison of demographic characteristics of clinical and normative population groups, for overall group, and stratified by age, and age and sex

\begin{tabular}{|c|c|c|c|c|c|c|c|}
\hline & \multirow{3}{*}{ Overall group } & \multicolumn{2}{|c|}{ By age } & \multicolumn{4}{|c|}{ By age and sex } \\
\hline & & \multirow{2}{*}{$15-18$} & \multirow{2}{*}{$19-25$} & \multicolumn{2}{|c|}{ Male } & \multicolumn{2}{|c|}{ Female } \\
\hline & & & & $15-18$ & $19-25$ & $15-18$ & 19-25 \\
\hline \multicolumn{8}{|l|}{ Married or De facto } \\
\hline Clinical \% (N) & $7.14(140)$ & $1.47(68)$ & $12.50(72)$ & $0(29)$ & $11.11(27)$ & $2.56(39)$ & $13.33(45)$ \\
\hline Normative $\%(N)$ & $11.71(165557)$ & $0.43(51849)$ & $16.86(113708)$ & $0.15(26513)$ & $11.79(56943)$ & $0.72(25336)$ & $21.94(56765)$ \\
\hline p & .093 & .191 & .323 & .835 & .913 & .175 & .163 \\
\hline \multicolumn{8}{|l|}{ Country of Birth } \\
\hline \multicolumn{8}{|l|}{ Australia } \\
\hline Clinical \% $(N)$ & $79.29(140)$ & $87.88(66)$ & $71.62(74)$ & $92.86(28)$ & $75.86(29)$ & $84.21(38)$ & $68.89(45)$ \\
\hline Normative $\%(N)$ & $69.92(170785)$ & $82.33(52444)$ & $64.42(118341)$ & $82.48(26780)$ & $64.43(59312)$ & $82.17(25664)$ & $64.42(59029)$ \\
\hline$p$ & $.016^{*}$ & .237 & .196 & .149 & .199 & .743 & .531 \\
\hline \multicolumn{8}{|l|}{ Aboriginal or Torres } \\
\hline \multicolumn{8}{|l|}{ Strait Islander person } \\
\hline Clinical \% $(N)$ & $1.46(137)$ & $1.54(65)$ & $1.39(72)$ & $0(25)$ & $3.7(27)$ & $2.5(40)$ & $0(45)$ \\
\hline Normative \% $(N)$ & $0.71(170987)$ & $0.94(52400)$ & $0.61(118587)$ & $0.92(26724)$ & $0.65(59398)$ & $0.95(25676)$ & $0.57(59189)$ \\
\hline & .296 & .617 & .396 & .630 & .049 & .313 & .612 \\
\hline \multicolumn{8}{|l|}{ Living with Parents } \\
\hline Clinical \% $(N)$ & $65.03(143)$ & $81.16(69)$ & $50(74)$ & $85.71(28)$ & $48.28(29)$ & $70.05(41)$ & $51.11(45)$ \\
\hline Normative \% $(N)$ & $56.49(178859)$ & $87.46(54625)$ & $42.88(124234)$ & $88.39(27856)$ & $46.26(62515)$ & $86.49(26769)$ & $39.45(61719)$ \\
\hline p & $.040 *$ & .114 & .216 & .658 & .827 & $.002 * * *$ & .110 \\
\hline
\end{tabular}

This article is protected by copyright. All rights reserved. 
Table 2

Comparison of education and employment characteristics of clinical and normative population groups, for overall group, and stratified by age, and age and sex

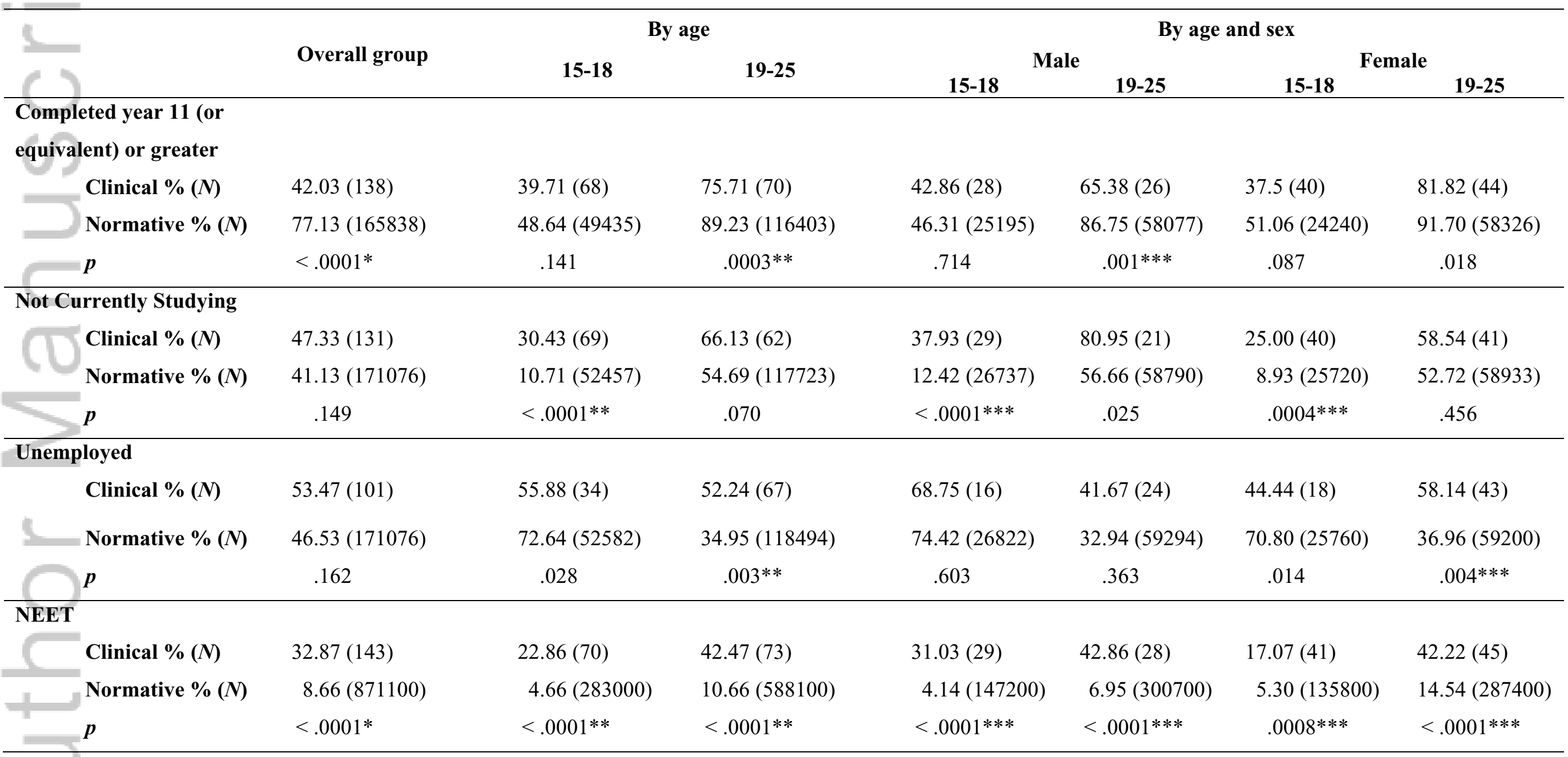

Note. $*=$ Significant at required critical value of $p<.05 . * *=$ Significant at required Bonferroni-corrected critical value of $p<.025 . * * *=$

Significant at required Bonferroni-corrected critical value of $p<.0125$

This article is protected by copyright. All rights reserved. 


\section{University Library}

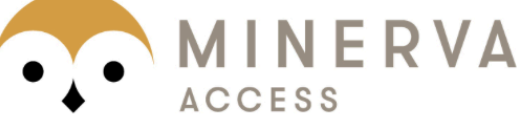

A gateway to Melbourne's research publications

Minerva Access is the Institutional Repository of The University of Melbourne

\section{Author/s:}

Caruana, E;Farhall, J;Cotton, SM;Parrish, E;van-der-EL, K;Davey, CG;Chanen, AM;Bryce, SD;Killackey, E;Allott, K

Title:

Vocational engagement among young people entering mental health treatment compared with their general population peers

Date:

2019-06-01

Citation:

Caruana, E., Farhall, J., Cotton, S. M., Parrish, E., van-der-EL, K., Davey, C. G., Chanen, A. M., Bryce, S. D., Killackey, E. \& Allott, K. (2019). Vocational engagement among young people entering mental health treatment compared with their general population peers. EARLY INTERVENTION IN PSYCHIATRY, 13 (3), pp.692-696. https://doi.org/10.1111/ eip. 12712.

Persistent Link:

http://hdl.handle.net/11343/284103 